\title{
Morphology by itself in planning the production of spoken words
}

\author{
ARDI ROELOFS \\ Max Planck Institute for Psycholinguistics, Nijmegen, The Netherlands \\ and \\ HARALD BAAYEN \\ University of Nijmegen, Nijmegen, The Netherlands \\ and Max Planck Institutefor Psycholinguistics, Nijmegen, The Netherlands
}

\begin{abstract}
The authors report a study in Dutch that used an on-line preparation paradigm to test the issue of semantic dependency versus morphological autonomy in the production of polymorphemic words. Semantically transparent complex words (like input in English) and semantically opaque complex words (like invoice) showed clear evidence of morphological structure in word-form encoding, since both exhibited an equally large preparation effect that was much greater than that for morphologically simple words (like insect). These results suggest that morphemes may be planning units in the production of complex words, without making a semantic contribution, thereby supporting the autonomy view. Language production establishes itself as a domain in which morphology may operate "by itself" (Aronoff, 1994) without recourse to meaning.
\end{abstract}

The mental lexicon, a speaker's mental storage of words, stands at the heart of spoken language production. In planning sentences, speakers access this storage of knowledge, which includes information on the meaning of words, their syntactic properties, morphological composition, and phonological properties. The meaning of words is involved in the early stages of language production, whereas the syntactic, morphological, and phonological properties serve as the basis for the subsequent processes of syntactic and morphophonological encoding (e.g., Levelt, 1989). It is therefore a critical question for a theory of language production to specify how the mental lexicon is organized and accessed.

The mental storage and planning of words is a central topic in research on speaking and has been studied intensively in the last decade (e.g., Levelt, Roelofs, \& Meyer, 1999). Until recently, however, this research has largely neglected the production of morphologically complex words. The standard view of morphology is that words may be built out of discrete units (morphemes) that contribute systematically to the meanings of the words containing them (e.g., Spencer, 1991). A morphologically complex word is semantically transparent if its meaning is compositional. For example, a word like happiness is semantically transparent, because its meaning is

We are indebted to Antje Meyer, Pim Levelt, Ken Forster, and three anonymous reviewers for helpful comments and to Daniëlle van den Brink for her help in preparing and running the experiment. Correspondence should be addressed to A. Roelofs, Max Planck Institute for Psycholinguistics, P. O. Box 310,6500 AH, Nijmegen, The Netherlands (e-mail: ardi@mpi.nl or baayen@mpi.nl). directly derivable from the meaning of its base morpheme happy and the suffix -ness. In contrast, even though it also contains -ness as a recognizable suffix, a word like business is not semantically transparent, although at some earlier point in the history of the English language it might have been. The transparent reading of business ("the property of being busy") is not encountered in contemporary language use. When the meaning of a morphologically complex word is not compositional but relates only arbitrarily or not at all to the meaning of the morphemes that constitute the word, the word is said to be semantically opaque.

The question we address in this paper is whether in language production these opaque complex words have morphologically decomposed or nondecomposed form representations. Butterworth (1983), among others, advanced the idea of a full nondecomposed listing of all complex forms for language production. According to Butterworth, most complex words in languages such as English and Dutch are so well known and have such simple structure that there is no need for on-line constituentdriven production (by contrast, in languages such as Hebrew, Finnish, and Turkish, the production of novel word forms is the rule rather than the exception). There is evidence from speech errors that supports the full-listing hypothesis for at least certain items in English. For example, Stemberger and MacWhinney (1986) observed that inflection errors occur less often for high- than for low-frequency inflected forms. For example, the error wait for waited (high-frequency form) occurs less often than weed for weeded (low-frequency form). This suggests that high-frequency forms are not assembled out of 
their constituent morphemes during production but that they are stored and retrieved as single units.

However, even in English and Dutch, speakers occasionally produce novel complex words for which they cannot have unitary form representations (e.g., Baayen, 1994; Baayen \& Renouf, 1996), such as breathcatchingly or nerdiness. And both the literature on speech errors involving other word types (e.g., Levelt, 1989; Stemberger, 1985) and recent on-line experimental results in our own laboratory (Janssen, Roelofs, \& Levelt, in press; Roelofs, 1996a,1996b, 1998) suggest that morphological constituents may well be planning units in spoken language production. Hence the full-listing hypothesis is probably incorrect for the mental lexicon as a whole. Nevertheless, it may be entirely correct for opaque complex words. For example, when a speaker wants to refer to "a written account of merchandise," it is not of any help in retrieving the target word invoice to know what the meanings of its constituents in and voice are.

This line of reasoning leads to the following hypothesis, which we refer to as the semantic dependency hypothesis: Morphological constituents are planning units in spoken word production for semantically transparent words only. That is, morphemes are associated with a word in memory only when they contribute systematically to the meaning of the word. For example, distributed connectionist (PDP) frameworks for cognitive psychology generally and for psycholinguistics specifically maintain that words are nothing besides their meaning-form correlations and that morphological structure emerges from those correlations (e.g., Plaut \& Gonnerman, 2000). In this view, morphology reflects a learned sensitivity to the systematic relationships among the meanings of the words and their sound forms. The opposing morphological autonomy hypothesis expresses a modular view of the encoding of word forms. In this view, the memory organization and encoding algorithms for word production aim at getting the forms right and are not concerned with semantic transparency. The autonomy view is implemented in the WEAVER++ model of spoken word production (Levelt et al., 1999; Roelofs, 1992, 1996a, 1996b, 1997).

In WEAVER++, an intended meaning is mapped onto an articulatory program for the corresponding word in two major steps. Lemma retrieval recovers the word's lemma, which is a memory representation of the syntactic properties of a word crucial for its use in sentences (Levelt et al., 1999; Roelofs, 1992). For example, a noun lemma links a lexical concept (the word's meaning) to the word's syntactic class (noun) and count/mass classification, and, for languages like Dutch, to its grammatical gender (e.g., neuter, nonneuter). Furthermore, a lemma contains abstract morphosyntactic slots whose values (e.g., number $=$ singular/plural) control processing at the next level of access, word-form encoding. In word-form encoding, morphological and phonological properties are retrieved in order to construct an articulatory program that appropriately encodes a lemma and the information given in its slots (cf. Levelt, 1989; Roelofs,
1997). Once the processes of conceptualization and lemma selection have been completed, the process of form encoding operates on the word-form representations regardless of whether or not the morphological constituents contribute systematically to the meaning of the whole word (i.e., whether the complex word is semantically transparent or opaque).

In the present paper, we concentrate on complex words in Dutch (WEAVER++ has been computationally implemented for the Dutch language). As concerns their formal behavior in the language, many opaque complex words are patterned after transparent complex words. This is most evident from the phenomenon of gapping in a conjunction (e.g., Booij, 1995). In Dutch, the noninitial morpheme of both transparent and opaque complex words can be omitted if it is identical with the noninitial morpheme of an adjacent complex word (if the morphemes are phonological words), as in the opaque conjunction of complex words voor-en nadeel (for voordeel en nadeel, English advantage and disadvantage). This does not hold for simple words like nagel (nail); for example, na-en vogel (for nagel en vogel, English nail and bird) is not well formed. This gapping phenomenon is most readily explained by assuming that the morphemic constituents of both opaque and transparent complex words are stored in memory and that form-encoding processes have access to these constituents in the planning of the words.

In examining the possible role of morphological constituent structure for opaque complex words in the planning of word forms, we employed the on-line preparation, or implicit priming, paradigm developed by Meyer (1990, 1991). The task falls into the general class of choiceresponse tasks. Priming and precuing of choice responses has been widely used in studying the planning of skilled action. For example, Rosenbaum (1980) used precuing to control the amount of preparation in arm movement. He manipulated the uncertainty in the specification of arm direction and extent and observed that as more information was available to allow preparation, movement initiation time decreased. The present implicit-priming task differs from precuing in that no explicit cues are given in advance but the cue is implicit in the response set. However, the logic is the same in that both implicit priming and precuing allow for the preparation of the action. In the implicit-priming paradigm, speakers first have to learn a set of prompt-response pairs and then have to produce the appropriate response when one of the prompts is shown. The big advantage of using paired associates compared with using a task like picture naming (which is among the most frequently used tasks in language production research) is that the responses do not have to refer to depictable entities, which gives more freedom in the selection of response words. Roelofs (1999) showed that implicit priming using paired associates and picture naming gives equivalent results.

An implicit-priming experiment consists of a number of alternating learning and test phases. Before each block 
of test trials, participants learn a small set of promptresponse pairs such as keyboard-input, knowledgeinsight, air-inflow. During the subsequent test phase, the speakers are shown (on a computer screen) per trial one of the first words of the pairs, called prompts (e.g., knowl$e d g e$ ), and they have to produce the corresponding second word of the pair as fast as possible without making mistakes (for knowledge they have to produce insight). The order of prompts across trials is random. The production latency, the interval between prompt onset on the computer screen and speech onset, is the main dependent variable. There are homogeneous and heterogeneous response sets. In a homogeneous set, the response words share part of their form, and in a heterogeneous set, they have nothing in common. For example, the responses share the first syllable (input, insight, inflow) or they are unrelated in form (input, misprint, doorstep). The same prompt-response pairs are tested in the homogeneous and heterogeneous conditions. Therefore, each word pair is tested under both the homogeneous and the heterogeneous condition, and all uncontrolleditem effects are kept constant across these conditions. Each participant is tested on all sets.

In testing monomorphemic words like insect, Meyer $(1990,1991)$ observed a preparation effect: The production latencies of the words combined in homogeneous sets in which they shared initial segments were smaller than those of the same words combined in heterogeneous sets. The form overlap between the responses in a homogeneous set allows speakers to prepare part of the response before the beginning of a trial, whereas such preparation is not possible in heterogeneous sets. Subsequent studies have shown that the size of the preparation effect depends on the morphological status of the shared string of segments (Roelofs, 1996a, 1996b, 1998). Strings of segments that constitute morphemes yield larger preparation effects than strings of segments that are not morphemes. For example, the preparation effect from sharing in is larger for response sets including morphologically complex words like input than for sets including morphologically simple words like insect. For monomorphemic words like insect, consisting of the single morpheme <insect $>$, sharing in allows for phonological preparation only. In contrast, for polymorphemic words like input, consisting of the morphemes $<$ in $>$ and $<$ put $>$, not only phonological but also additional morphological preparation is possible. For both insect and input, the first and second syllable have to be planned in the heterogeneous condition. However, for monomorphemic words like insect, only a single morpheme has to be planned in this condition, whereas for polymorphemic words like input, two morphemes need to be planned. Thus, when the first morpheme can be planned before the beginning of a trial (in the homogeneous condition), there is an extra benefit. This explains the much larger preparation effect for syllables that are morphemes. We refer to Roelofs's (1996a, 1996b, 1997, 1998) studies for detailed analyses of these experiments and quantitative WEAVER++ simulations of the results.
In the present study, we compared the preparation effect for transparent complex nouns in Dutch (like English input), opaque complex nouns (like English invoice, meaning "written account"), and morphologically simple nouns (like English insect). Does sharing the Dutch syllable/bei/ in opaque complex words like bijval (literally "additional fall," applause) yield the same preparation effect as /bci/ in transparent complex words like bijrol $(<\mathrm{bij}><\mathrm{rol}>$, literally "additional role," supporting role) or does it yield the same effect as in morphologically simple words like bijbel $(<$ bijbel $>$, bible $)$ ? According to the autonomy hypothesis, an opaque complex word like bijval is stored in terms of its constituent morphemes, $<$ bij $>$ and $<$ val $>$, thus it should behave like the transparent complex word bijrol $(<\mathrm{bij}><\mathrm{rol}>)$. In contrast, according to the semantic dependency hypothesis, the word bijval is stored as <bijval>, thus bijval should allow for the same amount of preparation as the simple word bijbel $(<$ bijbel $>$ ) and less than the transparent complex word bijrol $(<\mathrm{bij}><$ rol $>)$.

\section{METHOD}

\section{Participants}

The experiment was conducted with 18 paid participants randomly selected from the subject pool of the Max Planck Institute. All participants were native speakers of Dutch.

\section{Materials and Design}

The materials were obtained by an exhaustive search of the Dutch part of the CELEX lexical data base (Baayen, Piepenbrock, \& Gulikers, 1995). All prompts and responses were nouns. Each response was coupled with a prompt that the authors and the experimenter considered to be a strong and unambiguous retrieval cue for the corresponding target. There were 2 practice sets and 18 experimental sets of three prompt-response pairs each. The responses are listed in the Appendix.

Each set was tested in a separate block of trials. In nine experimental homogeneous sets, the responses shared the first syllable and in the remaining nine heterogeneous sets, there was no overlap. The shared syllables were "bij," "mis," and "na." As morphemes, they are a preposition, adverb, and preposition, respectively. Following Meyer (1990), we refer to the homogeneity variable as context. The same prompt-response pairs were tested in the homogeneous and heterogeneous conditions; only their combination in the sets differed. In three homogeneous and the corresponding three heterogeneous sets (the opaque condition), the responses consisted of one opaque and two more or less transparent complex words. In three other homogeneous and the corresponding three heterogeneous sets (the simple condition), the responses consisted of one morphologically simple word and two transparent complex words. In the remaining three homogeneous and the corresponding three heterogeneous sets (the transparent condition), the responses consisted of three transparent complex words. We refer to this variable as word type (transparent vs. simple vs. opaque). The presence of one simple noun mixed with two transparent complex words (the simple condition) should prevent morphological preparation; the crucial question is whether the same holds for the opaque words mixed with transparent complex words (the opaque condition).

The presence of a morphologically simple word mixed with morphologically complex words should prevent morphological preparation, because the constituent morpheme shared by the complex words is not suitable for all responses in the set. Preparation of the 
shared morpheme (e.g., <bij>) would be unsuitable for the trails at which the simple word has to be produced (and the morpheme $<$ bijbel $>$ has to be selected). Of course, the participants might still prepare the morpheme at the cost of a delayed response for the simple word. However, Roelofs (1999) has shown that the presence of an odd item in a set prevents preparation for the other items rather than delaying the odd item. We expect the same for the present experiment.

The materials were chosen so that the shared and remaining part of all words in the experiment corresponded to words in the Dutch language. This held not only for all complex words, but also for all simple words (just like "in" and "sect" in the English word insect happen to correspond to real words). For example, in the Dutch word bijbel (bible), both bij and bel correspond to real words: written "bij" (bee, near, at, etc.) and "bel" (bell, bubble) and spoken /bei/ (bee, near, at, etc.) and /bul/ (diploma). Thus, a difference in preparation effect between conditions cannot be due to a word/nonword difference between conditions. Furthermore, there were no phonological differences between the initial segments in the morphologically complex and simple words.

The order of sets was fully counterbalanced across participants. Six participants (Groups A and B) were tested first on the opaque sets, then on the transparent sets, and finally on the simple sets. Six other participants (Groups C and D) were tested first on the transparent sets, then on the simple sets, and finally on the opaque sets. The remaining 6 participants (Groups E and F) were tested first on the simple sets, then on the opaque sets, and finally on the transparent sets. Groups A, C, and E were first tested on the homogeneous sets and then on the heterogeneous sets. For Groups B, D, and $\mathrm{F}$ the order of testing was reversed. A different order of the three sets of a particular word type was used for each participant of a group, so that each set was tested once as the first, second, and third set of a particular word type. Each of the three prompt-response pairs of a set was tested six times within a block of trials. In the experiment, the order of testing the pairs was random, except that immediate repetitions of pairs were excluded. A different order was used for each block of trials and for each participant.

\section{Procedure and Apparatus}

All participants were tested individually. They were seated in a quiet room in front of a computer screen (NEC Multisync30) and a microphone (Sennheiser ME40). After the participant had read the instructions, the practice blocks were administered, followed by the experimental blocks. In the learning phase before each block of test trials, the pairs of a set were presented on the screen. As soon as the participant indicated having studied the pairs sufficiently, the experimenter started the test phase. The structure of a trial was as follows. First, the participant saw a warning signal (an asterisk) for $500 \mathrm{msec}$. Next, the screen was cleared for $500 \mathrm{msec}$, followed by the display of the prompt for $1,500 \mathrm{msec}$. The asterisk and prompt were presented in white on a black background. Finally, before the start of the next trial, there was a blank interval of $500 \mathrm{msec}$. Thus, a trial lasted $3 \mathrm{sec}$.

\section{Analyses}

After each trial, the experimenter coded the responses for errors. Four types of incorrect responses were distinguished: wrong words, dysfluencies, voice key errors, and time outs (responses longer than $1,500 \mathrm{msec}$ ). Incorrect responses were excluded from the statistical analysis of the latencies. The production latencies and error rates were submitted to by-participant and by-item analyses of variance with context and word type as within-participants factors in the byparticipant analysis and context as the within-items factor and word type as the between-items factor in the by-item analysis. No main or interaction effect for errors was significant both by participants and by items. Therefore, we report the means but not the test statistics for the errors.

\section{RESULTS AND DISCUSSION}

Table 1 gives the mean production latencies in milliseconds and the error percentages. The table shows that the words were produced faster in the homogeneous than in the heterogeneous condition. This latency difference, the preparation effect, was the same for the transparent sets and the opaque sets (73 and $76 \mathrm{msec}$, respectively) and much smaller for the simple sets $(30 \mathrm{msec})$. The transparent and simple conditions were also tested in one of the experiments reported in Roelofs's (1996b) study. Although the participants, the materials, the design, and the technique differed from the present experiment, the effect sizes were almost identical. In the earlier study, effects of 74- and 30-msec facilitation were observed for the transparent and simple conditions, respectively.

The statistical analyses of the latencies confirm these observations. The analyses yielded a main effect of context $\left[F_{1}(1,17)=40.86, M S_{\mathrm{e}}=2,342, p<.001 ; F_{2}(1,24)=\right.$ $\left.148.48, M S_{\mathrm{e}}=322, p<.001\right]$, but not of word type $\left[F_{1}(2,34)=5.01, M S_{\mathrm{e}}=963, p<.02 ; F_{2}(2,24)=1.25\right.$, $\left.M S_{\mathrm{e}}=1,932, p>.30\right]$. Most importantly, there was an interaction between context and word type $\left[F_{1}(2,34)=\right.$ $5.87, M S_{\mathrm{e}}=1,016, p<.006 ; F_{2}(2,24)=9.25, M S_{\mathrm{e}}=322$, $p<.001]$. Pairwise comparisons revealed that the effect of context was larger for the transparent than for the simple condition $\left[F_{1}(1,17)=11.35, M S_{\mathrm{e}}=729, p<.004\right.$; $\left.F_{2}(1,16)=11.31, M S_{\mathrm{e}}=366, p<.004\right]$ and larger for the opaque condition than for the simple condition $\left[F_{1}(1,17)=\right.$ $7.62, M S_{\mathrm{e}}=1,254, p<.02 ; F_{2}(1,16)=13.16, M S_{\mathrm{e}}=363$, $p<.002]$. Furthermore, the effect of context for the opaque condition and the transparent condition was the same $\left[F_{1}(1,17)<1, M S_{\mathrm{e}}=1,064, p>.84 ; F_{2}(1,16)<1\right.$, $\left.M S_{\mathrm{e}}=238, p>.76\right]$.

To summarize, the present experiment showed that in producing morphologically simple and complex nouns, a larger preparation effect was obtained when the shared initial syllable constituted a morpheme than when it did not, replicating Roelofs's (1996b) results. Importantly, the size of the morphemic effect is almost identical for semantically transparent and semantically opaque complex words, which suggests that morphemes are present in the memory representations of opaque complex words. Thus, the results clearly support the autonomy rather than the dependency hypothesis.

Of course, to accept that there is no difference between the transparent and opaque conditions means one

Table 1

Mean Production Latencies (in Milliseconds), Error Percentages, and Preparation Effects

\begin{tabular}{|c|c|c|c|c|c|c|}
\hline \multirow[b]{3}{*}{ Word type } & \multicolumn{4}{|c|}{ Context } & & \\
\hline & \multicolumn{2}{|c|}{ Homogeneous } & \multicolumn{2}{|c|}{ Heterogeneous } & \multicolumn{2}{|c|}{ Preparation } \\
\hline & $M$ & $E \%$ & $M$ & $E \%$ & $M$ & $E \%$ \\
\hline \multicolumn{7}{|l|}{ Complex } \\
\hline Transparent & 624 & 5.6 & 697 & 5.5 & -73 & 0.1 \\
\hline Opaque & 643 & 4.7 & 719 & 5.1 & -76 & -0.4 \\
\hline Simple & 665 & 7.1 & 695 & 4.1 & -30 & 3.0 \\
\hline
\end{tabular}


must accept a null hypothesis. However, the fundamental aim of the present study was to see whether we could replicate the morphological preparation effect for opaque complex words. Our having obtained the effect for opaque words shows that semantic transparency is not essential for morphological preparation and involves rejecting the null hypothesis. The fact that the size of the morphological effect was constant across the transparent and opaque conditions further suggests that transparency is entirely irrelevant. Of course, there may be a very small effect that has gone undetected. Empirically, the difference was $3 \mathrm{msec}$, but it is in the wrong direction for the transparency hypothesis (i.e., the morphological effect is larger for the opaque than for the transparent items).

One may wonder, however, whether a counter explanation is possible. Perhaps it was the case that the homogeneous set of complex words, regardless of opacity, had a common semantic thread running through the responses, which might have facilitated a parsing strategy. For example, all the "mis" words might have to do with negation (cf. misguide, misdeed, misname in English), but for the opaque words, what gets negated is not derivable from the meaning of the base. Perhaps that common thread is absent when a simple word is mixed with complex words. This counter explanation meets with a number of difficulties, however. Roelofs (1996b) has shown that a semantic relationship between the response words in a set hampers rather than facilitates the production of the words compared with a set with semantically unrelated words. But in the present study, complex words yielded a larger instead of a smaller preparation effect than did simple words, contrary to what the counter explanation predicts. Table 1 shows that there was a 20-msec difference between opaque and transparent words, which might suggest that semantic relatedness was effective. However, this difference was present in both the homogeneous and the heterogeneous conditions and not only in the homogeneous condition, as the counter explanation would require. Moreover, the difference was not statistically reliable $\left[F_{1}(1,17)=7.32, M S_{\mathrm{e}}=\right.$ $\left.1,030, p<.02 ; F_{2}(1,16)=2.76, M S_{\mathrm{e}}=1,367, p>.12\right]$.

\section{GENERAL DISCUSSION}

Our experimental results tie in nicely with the linguistic observation that many opaque complex words side with transparent complex words rather than with monomorphemic words with respect to their formal behavior. This finding is in line with the theory of autonomous morphology developed by Aronoff (1994), who showed that rules may govern the structure of morphologically complex words without simultaneously governing a semantic interpretation. Our study is, to our knowledge, the first on language production to offer online experimental evidence in support of Aronoff's position. Language production appears as a domain in which morphology may operate "by itself," without recourse to meaning. This suggests that it is the level of form repre- sentations in language production that drives word-form formation.

The present results challenge theories that assume that meaning determines whether morphological structure is stored with words in memory. For example, on a distributed connectionist account, morphology reflects learned meaning-form correlations (e.g., Plaut \& Gonnerman, 2000). Such an approach would predict a greater preparation benefit for transparent than for opaque words and no advantage of opaque words over morphologically simple words, contrary to the present results.

According to Plaut and Gonnerman (2000), however, a connectionist approach might exhibit morphemic effects in the absence of semantic transparency, depending on whether the language is morphologically rich or impoverished. For example, English makes relatively limited use of morphology, and the process of word formation mostly involves simple concatenation. By contrast, in a language like Hebrew, almost every word is morphologically complex, and word formation involves both concatenative and nonconcatenative processes. Empirical research on language comprehension suggests that morphological effects extend to semantically opaque items in a morphologically rich language like Hebrew (e.g., Frost, Forster, \& Deutsch, 1997) but not in a morphologically impoverished language like English (e.g., Marslen-Wilson, Tyler, Waksler, \& Older, 1994).

Plaut and Gonnerman carried out connectionist simulations in which morphologically related words varying in semantic transparency were embedded in either a morphologically rich or impoverished artificial language. They found that morphological effects increased with the degree of semantic transparency in both languages. Most importantly, morphological effects extended to semantically opaque items in the morphologically rich language (consistent with the empirical findings in $\mathrm{He}$ brew) but not in the impoverished language (consistent with the empirical findings in English). Thus, whether morphological effects for opaque words are obtained might depend on the degree of morphological organization of the language. However, as concerns morphological richness, Dutch (the language used in the present study) has a pattern more similar to that of English rather than Hebrew (e.g., Booij \& van Santen, 1998). Thus, the morphological preparation effect should not extend to opaque items, contrary to what the present experiment showed. Still, it may be important to repeat the present study in English and in Hebrew. We predict that the cross-linguistic difference between English and Hebrew observed for language comprehension will not be replicated for language production, but that the morphological preparation effect will be observed for opaque words in both English and Hebrew.

Studies of morphology not only have to take language specificity into account, but semantic transparency might also play a different role in language production than in comprehension, and, as a rule, results from comprehension cannot be generalized automatically to production, 
or vice versa. For example, Marslen-Wilson et al. (1994) conducted a series of cross-modal priming studies in which participants made lexical decisions to written targets that were preceded by auditorily presented primes. The results provided evidence for a critical role of semantic transparency in perceiving derived complex words in English (e.g., the transparent word happiness primes happy, but the opaque word apartment does not prime apart). Dutch is clearly more comparable with English than with languages like Hebrew, Turkish, and Finnish. However, the transparency hypothesis does not hold for production in Dutch, as the present study showed. Furthermore, it also does not seem to hold for comprehension in Dutch.

With the use of a primed lexical decision paradigm with visually presented primes and targets, Zwitserlood (1994) examined the role of semantic transparency for Dutch compounds. She observed that both transparent compounds (e.g., kerkorgel, church organ) and opaque compounds (e.g., drankorgel, drunkard) primed their morphological constituents (e.g., orgel). Furthermore, transparent compounds (e.g., kerkorgel) semantically primed associates of their constituents (e.g., muziek, music), whereas opaque compounds (e.g., drankorgel) did not. The effects for opaque compounds were the same as for monomorphemic words. These findings suggest that both transparent and opaque compounds are morphologically decomposed at the form level in perception but that, at the semantic level, the opaque items have a meaning representation that is not connected to the meaning of the morphological constituents. Thus, Zwitserlood reached a conclusion for comprehension in Dutch that is similar to the conclusion that we draw for production. The morphological constituents of opaque words may activate their meaning in comprehension, though. Schreuder, Burani, and Baayen (in press) observed that high-frequency stems of low-frequency derived words may semantically prime associates in Dutch. Clearly, there is a need for further investigation of the role of semantic transparency, both cross-linguistically and independently for comprehension and production.

To conclude, the present study provides clear evidence that once the processes of conceptualization and lemma selection have been completed in language production, the process of word-form encoding operates on the wordform representations regardless of whether the morphological constituents contribute systematically to the meaning of the word or not. Future studies should crosslinguistically examine the role of semantic transparency in production.

\section{REFERENCES}

Aronoff, M. (1994). Morphology by itself. Cambridge, MA: MIT Press.

BAAYEN, R. H. (1994). Productivity in production. Language \& Cognitive Processes, 9, 447-469.
Batyen, R. H., Piepenbrock, R., \& Gulikers, L. (1995). The CELEX lexical database (CD-ROM). Philadelphia: Linguistic Data Consortium.

BaAyen, R. H., \& Renouf, A. (1996). Chronicling The Times: Productive lexical innovations in an English newspaper. Language, 72, 69-96.

BooIJ, G. E. (1995). The phonology of Dutch. Oxford: Clarendon.

Boois, G. E., \& van SAnten, A. (1998). Morfologie: De woordstructuur van het Nederlands [Morphology: The word structure of Dutch]. Amsterdam: Amsterdam University Press.

Butterworth, B. (1983). Lexical representation. In B. Butterworth (Ed.), Language production: Vol 2. Development, writing and other language processes (pp. 257-294). London: Academic Press.

Frost, R, Forster, K. I., \& Deutsch, A. (1997). What can we learn from the morphology of Hebrew? A masked-priming investigation of morphological representation. Journal of Experimental Psychology: Learning, Memory, \& Cognition, 23, 829-856.

Janssen, D. P., Roelofs, A., \& Levelt, W. J. M. (in press). Inflectional frames in language production. Language \& Cognitive Processes.

LeVelt, W. J. M. (1989). Speaking: From intention to articulation. Cambridge, MA: MIT Press.

Levelt, W. J. M., Roelofs, A., \& Meyer, A. S. (1999). A theory of lexical access in speech production. Behavioral \& Brain Sciences, 22, $1-38$.

Marslen-Wilson, W. [D.], Tyler, L. K., Waksler, R, \& Older, L. (1994). Morphology and meaning in the English mental lexicon. Psychological Review, 101, 3-33.

Meyer, A. S. (1990). The time course of phonological encoding in language production: The encoding of successive syllables of a word. Journal of Memory \& Language, 29, 524-545.

MeYer, A. S. (1991). The time course of phonological encoding in language production: The phonological encoding inside a syllable. Journal of Memory \& Language, 30, 69-89.

Plaut, D. C., \& Gonnerman, L. M. (2000). Are non-semantic morphological effects incompatible with a distributed connectionist approach to lexical processing? Language \& Cognitive Processes, 15, 445-485.

Roelofs, A. (1992). A spreading-activation theory of lemma retrieval in speaking. Cognition, 42, 107-142.

Roelofs, A. (1996a). Morpheme frequency in speech production: Testing WEAVER. In G. E. Booij \& J. van Marle (Eds.), Yearbook of morphology 1996 (pp. 135-154). Dordrecht: Kluwer.

Roelofs, A. (1996b). Serial order in planning the production of successive morphemes of a word. Journal of Memory \& Language, 35, 854-876.

RoElofs, A. (1997). The WEAVER model of word-form encoding in speech production. Cognition, 64, 249-284.

Roelofs, A. (1998). Rightward incrementality in encoding simple phrasal forms in speech production: Verb-particle combinations. Journal of Experimental Psychology: Learning, Memory, \& Cognition, 24, 904-921.

Roelofs, A. (1999). Phonological segments and features as planning units in speech production. Language \& Cognitive Processes, 14, 173-200.

Rosenbaum, D. A. (1980). Human motor initiation: Specification of arm direction and extent. Journal of Experimental Psychology: General, 169, 444-474.

Schreuder, R., Burani, C., \& BaAyen, R. H. (in press). Parsing and semantic opacity. In E. Assink \& D. Sandra (Eds.), Morphology and the mental lexicon. Dordrecht: Kluwer.

SPENCER, A. (1991). Morphologicaltheory. Cambridge, MA: Blackwell. Stemberger, J. P. (1985). An interactive activation model of language production. In A. W. Ellis (Ed.), Progress in the psychology of language (Vol. 1, pp. 143-186). London: Erlbaum.

Stemberger, J. P., \& MacWhinney, B. (1986). Frequency and the storage of regularly inflected forms. Memory \& Cognition, 14, 17-26.

ZWITSERLOOD, P. (1994). The role of semantic transparency in the processing and representation of Dutch compounds. Language \& Cognitive Processes, 9, 341-368. 
APPENDIX

Response Sets

Word type: Transparent

Context: Homogeneous

Set 1: bijvak, bijnaam, bijrol (subsidiary subject, nickname, supporting role)

Set 2: nasmaak, nazorg, napret (after-taste, after-care, subsequent pleasure)

Set 3: misdruk, misoogst, miskoop (printing error, bad harvest, bad bargain)

Context: Heterogeneous

Set 4: misoogst, bijvak, nazorg

Set 5: napret, misdruk, bijnaam

Set 6: bijrol, nasmaak, miskoop

Word type: Simple

Context: Homogeneous

Set 7: bijbel, bijbaan, bijzin (bible, side-line, subordinate clause)

Set 8: nagel, najaar, naschrift (nail, autumn, postscript)

Set 9: missie, misbruik, misstap (mission, abuse, misstep)

Context: Heterogeneous

Set 10: nagel, bijbaan, misbruik

Set 11: bijbel, naschrift, misstap

Set 12: missie, bijzin, najaar

Word type: Opaque

Context: Homogeneous

Set 13: bijval, bijnier, bijzaak (approval, kidney, side-issue)

Set 14: nadeel, nagalm, nadorst (disadvantage, reverberation, after thirst)

Set 15: miskleun, misdaad, miskraam (blunder, crime, miscarriage)

Context: Heterogeneous

Set 16: miskleun, bijzaak, nagalm

Set 17: nadeel, miskraam, bijnier

Set 18: bijval, misdaad, nadorst

Note-In the opaque and simple homogeneous sets, the italicized response is the odd item. English translations of the pairs are given in parentheses.

(Manuscript received August 29, 2000;

revision accepted for publication May 11,2001.) 